\title{
INTEGRATION OF BIM AND ADVANCED DIGITAL TECHNOLOGIES TO THE END OF LIFE DECISION-MAKING PROCESS: A PARADIGM OF FUTURE OPPORTUNITIES
}

\author{
Aurora Abruzzini, Sepehr Abrishami \\ University of Portsmouth
}

\begin{abstract}
PURPOSE - At the end of a building's lifecycle, there are several limitations to the decision-making process. There is the lack of data available from the building's history, the difficulty in assessing the condition of a building, and the variety of stakeholders' needs that have to be satisfied. The purpose of this research is to answer the question: how would EOL DMP change when buildings will have been digitally built? The answer will be illustrated through a conceptual framework.

DESIGN/METHODOLOGY/APPROACH - A qualitative analysis of the existing literature has been performed to identify the elements within BIM and advanced digital technologies that could be of support to the decision-making process. The findings have been collected and summarised in a conceptual framework that has been validated and enhanced through online interviews with industry experts.
\end{abstract}

FINDINGS - The EOL DMP framework has identified that BIM technology would bring the benefit of providing the initial digital data source, from which machine learning and data analytics would then extract the relevant data needed to measure accurately the criteria during the analysis of the endof-life options put on the table.

ORIGINALITY - The findings of this research could contribute in developing the software modules making the bridge between BIM and machine learning technologies, to implement them in the end of life decision-making process.

KEYWORDS - BIM, end of life, decision-making process, circular economy, big data, machine learning, sensors, IoT 


\section{0 - INTRODUCTION}

Taking decisions when a building has reached the end of its lifecycle is never an easy task. The history of the building would be necessary to assess its condition. However, the building history has been an information often not available (Lavy \& Jawadekar, 2014). This data gap was caused by the absence of technology able to record and store them. Nowadays, BIM technology is providing a solution to this issue by storing the building data within a digital model (Corry et al., 2011, Ilter \& Ergen, 2015, Gao \& Pishdad-Bozorgi, 2019). Nevertheless, the amount of data stored within the digital model is becoming too big to be handled manually. To answer this problem, advanced technologies such as machine learning and big data analytics could be integrated in the processes to work with the digital model (Ahmed et al., 2017). However, this integration has not been implemented yet. Nevertheless, the question arises about how would the end of life (EOL) decision-making process (DMP) change, when the integration of digital technologies will become a reality.

The purpose of this research is to answer the question: how would EOL DMP change when buildings will have been built with BIM and other advanced digital technologies? The answer to this question will be illustrated through a conceptual framework identifying which technology will be of support in what phase to the decision makers throughout the EOL DMP.

This research is organised as follows. The first section presents the background literature, and is divided into four sections investigating: the extent and limitations of BIM usage in the Operation and Maintenance stage (O\&M); the increase in advanced digital technologies application; the pros and cons of each end of life option as well as the criteria used to select them; and the methods used for the DMP. The results of the literature review are then summarised in the conceptual framework. The second section illustrates the methodology applied to conduct both the literature review and the online interviews with industry experts. The third section presents the results obtained during the online interviews. The fourth section describes the development and the enhancement of the framework based on the interview results. The fifth section discusses the findings around the framework, necessary to make a reasonable and smart usage of it. Finally, the sixth section presents the conclusion of this research and gives suggestions for future research.

\section{0 - LITERATURE REVIEW}

To find an answer to the research question, it was necessary to have an overview of the current approach towards the end of life of buildings, and of the potential application of advanced digital technologies. The first step was to determine the extent to which BIM can be leveraged in the O\&M stage, taking into account the current limitations. Subsequently, the advanced digital technologies available on the market were analysed with respect to their potential applications in the last phase of 
a building's lifecycle. In addition, it was essential to assess what are the possible options when a building reaches the end of its lifecycle, to understand the pros and cons of each option, and to identify which criteria would influence the decision. Finally, the tools to support the decision-making process were examined and compared. The conclusions of these four themes have been summarised in the conceptual framework at the end of the section.

\section{1 - BIM IN OPERATION AND MAINTENANCE STAGE}

The data collected during O\&M stage is the starting point to allow the decision makers to take informed EOL decisions (Bullen \& Love, 2011). As such, it was also established as the starting point of this research.

\subsection{1 - POTENTIAL APPLICATION OF BIM TECHNOLOGY}

The data collected during the O\&M stage includes the geometry, location, manufacturing, and deconstruction methods of components as well as the history of the building's maintenance (Volk et al., 2014). Using computer-aided tools, as encouraged by Rosenfeld \& Shohet (1999), allows facility managers to extract and analyse data to support the DMP, therefore allowing taking more efficient decisions (Corry et al., 2011, Bilal et al., 2016, Shalabi \& Turkan, 2017). Simulation and visualisation tools (Cahill et al., 2012, Volk et al., 2014) can be used to reduce errors and to share the data when needed (Shalabi \& Turkan, 2017).

Building Information Modelling (BIM) allows to store data from the different stages of the building's lifecycle in a digital model of the building, also called as-built model (Corry et al., 2011, Yin et al., 2011, Cahill et al., 2012, Motawa \& Almarshad, 2013, Volk et al., 2014, Ilter \& Ergen, 2015, Correa, 2015, Bilal et al., 2016, Shalabi \& Turkan, 2017, Ahmed et al., 2017, Holzwarth et al., 2019, Gao \& Pishdad-Bozorgi, 2019). BIM can be used to identify inefficiencies and deterioration during the O\&M stage (Motawa \& Almarshad, 2013, Lavy \& Jawadekar, 2014, Akinade et al., 2020). Looking towards further potential applications, Ahmed et al. (2017) suggest that the digital model can be integrated with big data analytics. However, as-built data of the building is not accurate enough yet (Lavy \& Jawadekar, 2014), and this leads to incomplete, fragmented, and even obsolete data which is of no use to the FM. According to Volk et al. (2014), the stakeholders should push the integration of BIM to develop and digitalise the FM process, which can succeed only with a major digitalisation and automation of process in the construction industry (Volk et al., 2014).

The extant literature highlights that some applications of BIM in the O\&M stage are already happening. Corry et al. (2011) present a simulation process capable of defining the building's performance objectives by using scenario modelling from BIM data. Nakama et al. (2015) propose a web-based BIM system capable of integrating BIM data into the maintenance process as a source of 
information. Shalabi \& Turkan (2017) suggest that the retrieval of maintenance history data is necessary for an automated corrective maintenance process response to alarms given by FM systems such as building automation system (BAS) and building energy management system (BEMS). Correa (2015) takes BIM application a step further by proposing the integration of BIM with geographic information system (GIS) to pave the way toward the smart city concept. Smart cities, or city information modelling (CIM), is not a defined concept yet, and the content it should store has not yet been agreed on (Correa, 2015). The potentiality of CIM is to visualise the entire city, or even the entire country, and, if city perspective disciplines are integrated, it could incentivise the search of a better quality of life, to improve the socio-economic condition of people and to reduce the amount of waste produced (Ahmed et al., 2017).

BIM implementation has required the development of the industry foundation classes (IFC), an open standard format created to overcome interoperability issues between different BIM software (Shalabi $\&$ Turkan, 2017). One of the data formats available for FM is Construction Operations Building information exchange (COBie). COBie is an IFC based data exchange specification standard used to translate the information from the construction stage to the O\&M stage (Lavy \& Jawadekar, 2014). It defines the level of detail required for every technical equipment and stores the operation information of components. It is a valuable form of information for FM (Volk et al., 2014). The information should be collected throughout the planning, design, construction, and handover stages (Ilter \& Ergen, 2015, Shalabi \& Turkan, 2017). Handing over the information in COBie format to the facility manager can be translated into a saving of cost and time during the O\&M stage (Lavy \& Jawadekar, 2014). COBie also includes information about the roles and responsibilities during the O\&M stage, and information about the deconstructability of the building and its components (Volk et al., 2014). However, Shalabi \& Turkan (2017) demonstrate that several studies agree on there not being enough data for FM, for example: COBie does not include information about architectural or structural components (Volk et al., 2014).

\subsection{2 - FM LIMITATIONS IN USING BIM}

In the last decade, there has been a shift of interest in BIM research concerning the later stages of a building's lifecycle, because FM companies have expressed an interest in using BIM as-built models (Corry et al., 2011, Volk et al., 2014). The purpose of FM is to reduce the energy expenses and running costs, and increase the lifespan of the building and the user's satisfaction (Nakama et al., 2015). However, there are some issues concerning FM inefficiency. First, there is no unified interface for FM systems to exchange information, and there is a lack of ability to store and process big quantities of information (Bilal et al., 2016). Second, a lot of manual input is required that may result in inaccurate or incomplete data being input (Shalabi \& Turkan, 2017). Third, the efficiency of FM 
depends on the accuracy of the data produced in the previous stages (Lavy \& Jawadekar, 2014), which may not always be available, as stated previously. Finally, it is difficult to assess the building's performance using only utility bills (Corry et al., 2011).

Although the need for BIM implementation in O\&M stage has been acknowledged since 2010, according to Gao \& Pishdad-Bozorgi (2019), there is still a question on how to use BIM data to support the FM. To have an efficient FM process, as much information as possible is needed on the building's history (Cahill et al., 2012). Currently, the risk for the facility manager is that the information and its relative documentation are often not well maintained and, because of the lack of implementation of BIM in FM industry wide, quality control, assessment and monitoring are poorly done (Volk et al., 2014). To be used to its full potential, BIM data need to be updated regularly throughout the building's lifecycle, and O\&M aspects should be considered since the planning and design stage of the building's lifecycle (Lavy \& Jawadekar, 2014).

Nevertheless, Shalabi \& Turkan (2017) have demonstrated how digital controllers can support the facility manager in optimising and monitoring the building's performance using a computerized maintenance management system (CMMS) as database. Prior to that, Correa (2015) suggests that the building's performance could be assessed in real time using sensors communicating with the BIM data repository. To have an intelligent management system, it is necessary to understand the patterns of the data produced by sensors. Ahmed et al. (2017) propose to use Big Data analytics to enhance the FM process. Within the FM, maintenance is one of the main activities to take care of. Maintenance consists in ensuring that the building keeps fulfilling the designed function for as long as possible (Ilter \& Ergen, 2015). There are three types of maintenance (Rabatel et al., 2011, Motawa \& Almarshad, 2013, Palem, 2013, Bilal et al., 2016, Shalabi \& Turkan, 2017). The first type is preventive or planned maintenance, usually instructed by the manufacturer. The second type is corrective maintenance: reacting to a fault or failure. The third type is predictive maintenance: detecting anomalies with the help of sensors to intervene before the failure happens. Palem (2013) states that both preventive and corrective maintenance are inefficient. The first one because it is costly and might happen when the system is still functioning, and the second one because it happens after the system has failed, therefore extra time is needed to fix the issue. Palem (2013) recommends using predictive maintenance as it reduces both the costs and the time spent. In order to apply predictive maintenance, remote sensor monitoring and real-time processing are fundamental (Palem, 2013). Furthermore, the deterioration of the building can be assessed by analysing data from the digital model (Motawa \& Almarshad, 2013).

Kim et al. (2010) have applied sensors to monitor pipeline functioning that have allowed locating the faulty object for active and corrective maintenance. Bilal et al. (2016) and Ahmed et al. (2017) have 
instigated the application of big data analytics in predictive maintenance, to inform the facility manager about the imminent failure or breakdown of equipment. Ahmed et al. (2017) add that due to the high reliance of industrial facilities on electro-mechanic equipment, big data analytics would be of big support for predictive maintenance. Shalabi \& Turkan (2017) propose to use 3D IFC-BIM linked with sensors to support CMMS in the visualisation and communication of problems.

The usage of BIM and digital models in FM process is in the early development stage and is still being investigated. This is further demonstrated by the call for grants of Horizon 2020, a research programme from the European Commission (2018). The five ongoing research projects targeting BIM in O\&M and EOL stages are:

1. BIM4REN (CORDIS, 2018a): the exploitation of BIM potential for energy renovation of existing buildings for the whole construction value chain;

2. BIMERR (CORDIS, 2019a): the development of a toolkit to support stakeholders during the renovation process of existing buildings;

3. ENCORE (CORDIS, 2019c): the development of BIM tools to assist stakeholders and facilitate information exchange during the renovation lifecycle;

4. BIM4EEB (CORDIS, 2019b): the development of a BIM toolset to support designers and construction contractors in providing attractive solutions for building retrofitting;

5. BIM-SPEED (CORDIS, 2018b): standardisation of procedures to provide $60 \%$ energy saving and reduce renovation time by $30 \%$ with BIM cloud platform and BIM interoperable tools

These projects are mobilising owners, consultants, contractors, public authorities, and universities from almost all countries in the European Union.

\section{2 - ADVANCED DIGITAL TECHNOLOGIES}

The AEC industry is very under-digitalised. Compared to other industries, it is the one investing the least in digital technologies (Blanco et al., 2018) due to a lack of understanding of the benefits of advanced technologies and a fear of having human jobs replaced by machines (Whitlock-Glave et al., 2019). However, a growing trend is being seen towards digitalisation of processes and technology throughout the whole lifecycle (Correa, 2015, Holzwarth et al., 2019, Whitlock-Glave et al., 2019). To develop the automation of tasks, a further step should be taken towards the integration of artificial intelligence (AI), machine learning, and big data analytics (Correa, 2015).

As mentioned above, the utilisation of sensor networks is increasing (Ahmed et al., 2017). Each sensor installed describes one specific property and when the sensors interact with each other, it is possible to analyse them and recognise behavioural patterns and therefore identify anomalies (Rabatel et al., 2011). The building's components' performance can be monitored (Zhengwei \& Gongsheng, 
2013) and the data collected can be used to find solutions (Blanco et al., 2018). Sensors can be used to measure equipment's performance (Cahill et al., 2012, Palem, 2013), and to monitor the structural health of the building (Haque et al., 2020). However, the sensors are often presented as a list and organised by number and location, which is not practical because it makes it difficult to visualise their position (Shalabi \& Turkan, 2017). They are also de-calibrated because of a lack of awareness about their importance (Zhengwei \& Gongsheng, 2013).

To combine thousands of sensors, the Internet of Things (IoT) can be used (Bilal et al., 2016). IoT is a tool that allows the communication and interrelation between the FM interface and the sensors installed (Asensio et al., 2014). It can also collect data about the building's usage through smart home applications (Holzwarth et al., 2019), to create value when planning a new building by analysing the usage history of other buildings. Sensors and IoT produce a data deluge that needs to be filtered and organised. This can be done only by introducing AI, machine learning and data analytics. A massive amount of data is needed to train the AI from past experiences (Blanco et al., 2018). Following that, the enhanced FM platform can collect and analyse the data produced by the sensors to propose realtime solutions. This means prioritising predictive maintenance that reduces the costs and downtime of the intervention (Blanco et al., 2018). Callow et al. (2013) have developed an AI-based bridge deterioration modelling technique that uses backward predictive modelling to reduce the uncertainties of long-term predictions. Nevertheless, there are some questions being addressed about AI liability (Whitlock-Glave et al., 2019) and about AI and human interaction to counter against the fear of having humans replaced by machines, a human in the Loop process (Luna, 2020). One of the interesting branches of AI is machine learning. It consists of both supervised and unsupervised learning techniques (Blanco et al., 2018), and it has the capability of classifying, clustering, associating, and numericly predicting (Bilal et al., 2016). Machine learning improves from and through experience (Whitlock-Glave et al., 2019). Its application is being investigated in the field of image recognition for classification and quality control (Han \& Golparvar-Fard, 2015, Blanco et al., 2018, Haque et al., 2020) as well as to predict litigations outcomes (Bilal et al., 2016).

The last interesting advanced technology is big data analytics. It can collect and analyse data, and then infer or formulate conclusions, for example, to assess when an equipment is about to break or requires an upgrade (Bilal et al., 2016). However, its biggest potential in FM would be seen when applied to assessing the sustainability and tracking of energy consumption (Ahmed et al., 2017). The integration of big data analytics would be possible because the digitalisation of the processes would increase the production of data (Holzwarth et al., 2019) and there would be massive data being generated from devices and sensors (Bilal et al., 2016). BIM would become the building's data repository. However, if BIM extends to the concept of smart cities, big data analytics could be used 
for prediction assessment of city level phenomena (Correa, 2015). However, the application of big data analytics to a single BIM model would not be meaningful, as a single model does not contain enough data.

\section{3 - END OF LIFE}

RIBA Plan of Work (2020) reserves the last of its 8 stages to the O\&M of the building, which is not only the longest stage in the building's lifecycle, but also fundamental for the EOL stage. This is an important stage of the building's lifecycle, too often neglected as reflected in the limited literature available on the topic.

\subsection{1 - EOL OPTIONS}

Upon reaching the end of the lifecycle, there is the difficult decision of what to do with the building (Bullen \& Love, 2011). One option would be demolition, because of the poor condition of the building, the lack of architectural significance, the opportunity to maximise the land value, and the estimation that it would be too much work to renovate the building (Thomsen \& Flier, 2008, Bullen \& Love, 2011, Baker et al., 2017). However, it is not an environmentally friendly option (Bullen \& Love, 2011). Another similar option would be deconstruction. It is more cost effective because it reduces the cost of the landfill (Chau et al., 2017, Hübner et al., 2017). It also reduces the impact of the EOL stage thanks to the disassembling of the parts to reduce waste (Chau et al., 2017). However, there is a lack of legislation about deconstruction. Architects and engineers are not obliged to ensure the deconstructability. Akinade et al. (2020) suggest that the deconstructability should be considered at the planning and design stages, by identifying materials with EOL value and deconstruction methodologies. BIM would benefit deconstruction as it would provide the up to date building data (Volk et al., 2014).

A different option would be renovation. The goal is to extend the operating life of the building by 30 to 50 years, by doing some remodelling, replacing entire parts, or adding new parts (Rosenfeld \& Shohet, 1999). Different types of renovation have to be analysed prior to choosing (Thomsen \& Flier, 2008, Yin et al., 2011). The main reasons to choose renovation are heritage value, quality of components, government incentives, and adapting the building to the changing preferences and needs of users (Thomsen \& Flier, 2008, Tupenaite et al., 2010, Baker et al., 2017). Renovation too would benefit from BIM implementation for the same reason as deconstruction (Volk et al., 2014). Finally, there is reconstruction. It is often the costliest option with high direct and indirect costs (Rosenfeld \& Shohet, 1999). It is important to consider if the function of the building can be interrupted to renovate/reconstruct (Rosenfeld \& Shohet, 1999). 


\subsection{2 - CRITERIA TO BE ANALYSED}

Different criteria can be considered to identify the most appropriate option. The criteria are influenced by social, political, economic, cultural, scientific, and technical factors. It is crucial to analyse them as they can lead the project to failure or to success (Tupenaite et al., 2010). The first criterion is the building's performance. Yin et al. (2011) identified that an analysis of the energy building performance is necessary since old buildings could perform worse, a critical issue according to Bullen \& Love (2011) and Chantrelle et al. (2011), a renovation could bring energy savings of $40 \%$ to $74 \%$. Chantrelle et al. (2011) and Yin et al. (2011) are also concerned about the thermal comfort of the users and the heat loss. Stage et al. (2017) state that the embodied carbon and energy assessment allow to measure the option's environmental impact. Thomsen \& Flier (2008) and Medineckiene \& Björk (2011) agree that the simulation of building performance indicates how much a solution fits the objectives.

The second criterion is the financial aspect. Rosenfeld \& Shohet (1999), Yin et al. (2011), Chantrelle et al. (2011), Fregonara et al. (2017), Baker et al. (2017) and Bender (2019) agree that the budget can be a limitation, therefore requiring an extensive economic comparison of the alternatives. Although being a fundamental criterion, it appears that the DMP is tired of using criteria that converge into a financial analysis (Bullen \& Love, 2011).

The third criterion is the legislation. Bullen \& Love (2011) state that the applicable regulations can influence the choice of the option, for example, when new norms impose some renovation or change the urbanistic constraints. Furthermore, the lack of legislation, as for deconstruction (Akinade et al., 2020), also influences the DMP.

The fourth criterion is the physical condition of the building. A preassessment of the condition of all building's components is necessary prior to any consideration or discussion (Rosenfeld \& Shohet, 1999). The condition of the structure and services is a fundamental element that itself tilts the balance between demolition or renovation (Thomsen \& Flier, 2008, Bullen \& Love, 2011).

The fifth criterion is the social aspect, and more specifically, the impact on the surrounding community (Baker et al., 2017). The social factors include proximity to transport, location within the city, streetscape and the consolidation of the community (Bullen \& Love, 2011).

The sixth criterion is the environmental and sustainable aspects, beyond the strict energetic performance already mentioned. Although there is still a lack of encouragement from governments towards sustainable options, Thomsen \& Flier (2008), Bullen \& Love (2011), Baker et al. (2017), Fregonara et al. (2017) and Chau et al. (2017) confirm that the interest in sustainability is increasing among the industry. 
The seventh and last criterion is the urban environment. The presence of a master plan and the geographical context in which the building has been built have an influence on the DMP.

Apart from the criteria for the analysis of options, another important element to consider is the stakeholders involved in the EOL stage. There are different stakeholders with different priorities (Tupenaite et al., 2010, Baker et al., 2017). The most important stakeholders are the owner, because they choose in the end, and the designer, because their analysis will determine which options are feasible or not (Vieira \& Horvath, 2008, Bullen \& Love, 2011). Another level of priority is given by the sector of the owner: public or private. The private sector is more interested in economic and technological advantages, while the public sector is more interested in economic and environmental advantages (Fregonara et al., 2017). It is difficult to reach a consensus between the stakeholders (Holzwarth et al., 2019), however, every stakeholder preferences should be considered during the analysis (Tupenaite et al., 2010).

\section{4 - DECISION-MAKING ANALYSIS}

The decision-making analysis is a methodology for selecting the best between numerous alternatives (Tupenaite et al., 2010). Some tools that have been developed to support the analysis process are a transformation meter in the Netherlands, used to assess the adaptation potential of a building's function to another, and IconCUR, which is a 3D spatial tool used to assess the building's performance during the lifecycle using multicriteria (Baker et al., 2017). Buyle et al. (2013) propose a tool investigating the environmental impact of a product or a process. However, it is difficult to analyse the environmental impact of products or services, especially at EOL, because of the complexity and because of data requirements not being fulfilled (Vieira \& Horvath, 2008).

The difficulties faced during the decision-making analysis include having to deal with conflicting objectives (Chantrelle et al., 2011), trying to grasp information as much detailed as possible without any rules, model or standards (Nakama et al., 2015), and justifying the decision made because of a lack of references (Bullen \& Love, 2011). To overcome this issue, Fregonara et al. (2017) recommend that according to circular economy theory, operation and management and EOL stages should be considered together. There are two main decision-making analysis methods. The first one is the cost/benefit analysis (CBA), defined as the preferred solution based on synthetic economic indicators (Fregonara et al., 2017). This method is used to determine the optimum return on investment (Bullen \& Love, 2011). However, it is a mini analysis only looking at one criterion (Roy, 1985). The second decision-making analysis method is the multicriteria analysis. As the name explains, it is an analysis method that looks simultaneously at numerous parameters and provides a plurality of optimised options (Chantrelle et al., 2011). Tupenaite et al. (2010) and Velasquez \& Hester (2013) recommend using multicriteria analysis in the built environment especially because of the upcoming use of 
advanced technology implementations. The multicriteria analysis' popularity has grown because it allows a multi-dimensionality so to include environmental and social factors. In addition, the calculation can be done according to different stakeholders' opinions, although the owner's opinion has the biggest impact on the results (Medineckiene \& Björk, 2011).

There are 3 families of multicriteria methods: multi-attributes analysis, outranking analysis, and participatory analysis (Roy, 1985, Vincke, 1989). Since the decision cannot be separated from the DMP itself, it is important to define in advance what the possible options are and what criteria are going to be used for the analysis (Roy, 1985). Research shows that multicriteria analysis performs better than CBA, specifically when looking at environmental and sustainability aspects (Marleau Donais et al., 2019). Multicriteria analysis also facilitates the debate on the pros and cons of each alternative by providing trade-offs of gains and losses for each stakeholder (Saarikoski et al., 2016).

In the AEC industry, multicriteria analysis is being used by the government in addition to the CBA for transport related processes. The combination of these two analysis methods has been developed in the Evaluation Framework of Environmental impacts and Costs of Transport, which is a framework for sustainable transport (Beria et al., 2012).

\section{5 - CONCEPTUAL FRAMEWORK}

The framework summarises the findings from the literature review: how the EOL DMP is organised; what criteria should be used to run the analysis to rank/select the best options; what is the level of involvement of the stakeholders; what data is being used and where it comes from; and where could the digital technologies be introduced to become a support to the DMP.

The EOL DMP follows a simple procedure. Once the decision to intervene is taken, different sets of elements are analysed to determine what the best course of action could be, and to elaborate a ranking of the possible options. The literature review looked at a number of papers describing this process, but - although there is a general understanding that EOL decisions for buildings can lead to two options: renovation or demolition - these papers all looked at one single option at a time (i.e. how to optimise or manage it). No paper taking into consideration the EOL DMP as a whole was found. The research aimed at taking into consideration as many EOL options as possible, the main two being renovation and demolition. Within these two categories, many sub-options are possible. The renovation options can be ranked based on the extent of the renovation and whether some elements of the building could be reused or recycled. The demolition options, similarly, can be ranked based on whether the whole asset is to be demolished or just a part of it; if a reconstruction is being considered; and whether deconstruction methods can be used to recycle some parts. 
An analysis of different criteria must be undertaken to rank and compare the options. The papers collected in the literature review use or propose to use 18 different criteria. These 18 criteria have been grouped in 6 categories: the building's physical condition criteria, the financial criteria, the building's performance criteria, the environmental criteria, the social criteria, and the urban realm criteria (detailed in Fig.1). These criteria may not always be applicable, depending on the private or public sector or the function of the asset, and these were some of the main elements that needed to be validated through the interview process.

There are two types of analysis that can be done to determine the best option. Although it resulted from the literature review that the most common analysis done is a CBA, more recently some version of MCA has been catching on. As illustrated in the literature review, the MCA has the advantage of considering those criteria that cannot be financially quantified, therefore that cannot be considered within a CBA. If the criteria are attentively observed, it is true that many of them are interrelated and, in the past, some methods have been defined to associate a financial value to some criteria such as, for example, the asset performance that can be financially assessed using the expenses related to it. However, some other criteria, like the social, environmental, or urban realm criteria, are harder to define in financial terms (Medineckiene \& Björk, 2011). This is where the MCA has an advantage over the CBA and has therefore started to take foot. In addition, such methods facilitate the identification of trade-offs between the criteria and provide transparent information to fuel the debate between the stakeholders (Saarikoski et al., 2016).

Two stages have been identified as being significant for the stakeholders' involvement. First, at the beginning of the DMP, the stakeholders have the power to influence the route to be taken and the options to keep on the table, i.e., whether to pursue the renovation route or the demolition route, based on their needs. Second, during the analysis process, the stakeholders can express preferences on the importance of some criteria over others. The stakeholders involved can be divided into 2 categories: internal stakeholders, such as the owner, its advisory service, and con sultants, and external stakeholders, such as the local authorities and advocacy groups potentially present in the surrounding area.

The conceptual framework (see Fig. 1) connects the different elements seen above and shows the information flow between them. It also integrates where and when BIM and other advanced technologies could be integrated to provide support to the DMP. The flow of information goes from the top to the bottom of the framework. It all starts with the information repositories that have been identified: the asset's digital model, the technological opportunities that would become available, and the most recent laws and regulations. From these repositories, the literature suggests that the technologies of machine learning and big data analytics could extract the information and give a more 
accurate measurement of the criteria for each of the options. Following the quantification of the criteria, the aggregate analysis methods that could be used are the CBA and the MCA, to rank the options to support the DMP. The two main stages of stakeholders' the intervention have also been represented: their influence on the choice of options and their preferences on criteria weighting. [Insert Fig. 1]

\section{0 - METHODOLOGY}

This research has been organised around five objectives, which are illustrated in the methodology flowchart (Fig. 2). These objectives are:

1. To establish the extent of BIM and advanced technologies usage in Operation and Maintenance stage.

2. To understand what criteria are being considered when demolition or renovation decisions are taken.

3. To analyse the decision-making process methods.

4. To develop a conceptual framework.

5. To validate the framework.

This research consisted in collecting and investigating two types of qualitative data. The first type of data was collected in the literature review, and concerned the first three objectives. The data was analysed through qualitative content analysis and summarised in the conceptual framework above, the fourth objective. The second type of data was collected through online interviews with sector experts to validate the conceptual framework. As recommended by Braun \& Clark (2008) for analysing qualitative data, a thematic analysis was carried out to determine common patterns in the participants' answers, leading to the development of the EOL DMP framework.

[Insert Fig. 2]

\section{1 - METHODOLOGY AND SCOPE OF THE LITERATURE REVIEW}

The academic articles and research projects that compose the literature review have been searched and selected by using Google Scholar - as recommended by the University of Portsmouth academic standards for its wider approach covering the Scopus and WoS databases (Martin-Martin et al., 2018)

- and by applying the snowball strategy to explore further cited and referenced articles on similar topics (Naderifar et al., 2017). The articles for this research were identified by searching keywords, going from broad (BIM, end of life) to specific terms (renovation, machine learning, MCA versus CBA). Hundreds of papers were screened and only those focusing on the four research objectives met 
eligibility criteria. The 57 selected articles were then analysed using NVivo, a qualitative analysis software.

The search focused on the last 30 years of research because the first mentions of BIM date to the 1990's (Van Nederveen \& Tolman, 1992). Where possible, preference was given to more recent publications in order to collect the latest research findings.

\section{2 - METHODOLOGY AND SCOPE OF THE VALIDATION FIELDWORK}

The data collection method that was chosen was semi-structured interviews. The primary choice would have been to organise focus groups, but the social distancing requirements set up because of the COVID-19 pandemic forbade it.

\subsection{1 - ADVANTAGES AND DISADVANTAGES}

Compared to other methods of qualitative data collection, the interview was chosen because it allowed the researcher to explore, through open and verification questions, the past and present experiences of the participants in facing EOL decisions for buildings. The semi-structured interview had the advantage of providing both the interviewer and the participant with an outline of the discussion topics (Bell, 2014).

\subsection{2 - SAMPLING CRITERIA}

The aim of this empirical stage was to validate the conceptual framework by collecting the experts' experiences, without any intention of measuring a socio-economic phenomenon. The sampling method adopted was the probabilistic qualitative sampling (Djamba \& Neuman, 2002), because the sample size did not need to be statistically stratified and structured. A limited number of interviews were deemed satisfactory and, as suggested by Robinson (2014), the effort was concentrated on capturing the diversity of opinions from the experts, to allow the formulation of generalisations and commonalities. Two dimensions define this diversity:

- Sector:

- Public sector;

- Private sector;

- Role:

- The building owners, from both the public and private sectors, and their representatives/assistants;

- The technical consultancy firms providing professional services to analyse scenarios, design feasible options, assess their costs and impacts, including also some important FM services producing key data on the structure/maintenance of a building; 
- The local authorities involved in different authorisation/clearance processes;

- The advocacy groups affected by the impact of such EOL decisions, pushing for consideration of their point of view or representing wider/transversal interests and expertise;

- The researchers involved in the development of digital technologies in the later stages of a building lifecycle.

Concerning the geographical coverage, both the UK and the EU countries were considered eligible because, as with pre-Brexit, professional practices, the access to technologies, and the regulatory environment are sufficiently harmonised and equivalent not to bias analysis. The participants were identified by exploiting the following information sources:

- Professional associations, mostly for real estate managers;

- The participants in ongoing Research \& Development projects about building renovation, which helped to cover multiple roles and to capture persons involved in innovation advances;

- Personal contacts and acquaintances, with such experience.

The experts' experiences were collected through the population of stakeholders involved in the EOL DMP.

The target was set to perform 10 to 20 interviews with an expected non-response rate of minimum $70 \%$. To achieve this target, 104 invitations were sent and 13 participants accepted to take part in the interview process that occurred during the months of July and August 2020 under worldwide pandemic lockdown.

\subsection{3 - INTERVIEW DESIGN}

The interview grid was developed, based on the conceptual framework, to answer 3 main questions:

1. Does the conceptual framework reflects the current practice and lets room for future developments?

2. Does the conceptual framework fits the needs of the different stakeholders involved in the DMP?

3. Does the conceptual framework identify when and how digital technologies could/should be used to support the DMP?

The interview grid was articulated in 4 parts, each one containing 2 to 3 questions, for a total of 10 questions:

1. The interviewees' introduction and description of their experience;

2. The screening phase organisation for the selection of options; 
3. The criteria assessment and analysis method;

4. The potential benefits of advanced data technologies.

The interviews were carried out either on Google Meet or by telephone, and they had an average duration of 45 minutes. To facilitate the extraction and analysis of the data collected, each interview was transcribed with Otter.ai, a speech to text transcription software, from the interviews' audio recordings. The participants were required to give their consent prior to the recording in order to carry out the interviews in full respect of the University of Portsmouth ethics policy. The analysis of the interview transcripts was then carried out with NVivo to ensure the respect of academic research requirements. A thematic analysis was executed to identify the common patterns and thoughts between the participants. The coding process majorly consisted in identifying positive or negative answers and in classifying the supporting reasoning. These results are highlighted in the next section and are presented following the 4 parts of the interview grid. The findings were then used to develop the EOL DMP framework in section 4.

\section{0 - RESULTS}

\section{1 - PART 1: PARTICIPANTS’ BACKGROUND AND EXPERIENCES}

Out of the 13 interviewees, 4 had experience in the private sector, 6 in the public sector, and 3 people had experience in both sectors (Fig. 3). In addition, the roles that were interviewed were 5 decision takers, 5 assistants to the decision takers, 4 consultants, and 2 researchers (Fig. 1). Unfortunately, there were no replies from people working with the local authorities or in the local advocacy groups. Still, the universe of interviewees was varied enough to meet the planned target.

\section{[Insert Fig. 3]}

Based on the interviewees' experience, the trigger events that would mark the beginning of the DMP were identified and grouped into 2 categories: internal and external triggers. The internal triggers concern the asset itself, such as the physical condition of its elements, the energy and thermal performance, the utilisation rate, the suitability of the asset for its function, and the costs spent to run the asset. The external trigger concerns surrounding environment of the asset, such as the change in urban planning, the change in environmental legislations, or even the happening of crises, like the current COVID-19 pandemic, that could be seen as opportunities. There was a sense of consensus on what were the major triggers. The most recurring trigger appears to be the costs spent to run the asset. The second most recurring triggers were, with equal importance, the energy and thermal performance of the asset and the change in environmental legislations, which are two faces of the same medal. The third most recurring trigger was the change in legislations concerning urban planning and building 
standards. The trigger events were defined as being the moment in which the asset could be considered no longer fit for purpose and interventions were required.

\section{2 - PART 2: SCREENING PHASE ORGANISATION AND ACTORS INVOLVED}

There was a unanimous consensus concerning the organisation of the screening phase. Whether the DMP happens in the public sector or in the private sector, the phases to go through remained the same. First, the owner starts the process and consults with technical experts to get an analysis of the feasible options. Then, the owner decides which option to implement. The consensus then differed between the private and public sector on what the priorities were. While the private sector would be more concerned in getting a financial profit, the public sector would be more concerned in "giving the good example", as said by one of the interviewees, therefore prioritising the environmental issues as they appear to be the current trend.

In regard to involving the stakeholders at this initial stage, the majority, 8 against 5 , showed a positive response to having them involved to share their needs and preferences, and to quote another interviewee "the more information better" at this stage. The interesting result was that the majority of positive responses came from the public sector experts. It seemed that since the priority in the private sector would be of a financial nature, the less stakeholders' involvement there is, the better, as their involvement would increase the risk of having to satisfy too many interests to the detriment of the asset owner's interest.

\section{3 - PART 3: CRITERIA USED FOR ANALYSIS AND ANALYSIS METHOD}

From the literature review, 18 criteria were identified as being useful in the analysis process. The participants were asked to say whether these 18 criteria, based on their own experience, were being applied or not, and if not, whether the reason was because of a lack of data or because of their nonrelevance. Overall, the outcome was a strong confirmation that the 18 criteria are currently being used and probably will still be used in the future. However, some of them resulted being used almost all time, while others had a more limited application. As shown in Fig. 4, the criteria that appeared to be always used were the condition of the structural elements of the asset and the possible cost of the options considered.

\section{[Insert Fig. 4]}

However, the utilisation of the criteria did not reflect the importance given to the criteria. It seemed that the top 3 most important criteria to analyse were: the budget available, the condition of the structural elements of the asset, and the transport available to reach the asset, based on the percentage of mentions through the interview process (see Fig. 5). 
If we look at the criteria that appear to be less used, the interesting result is that the relevance of a criterion seems to depend on the sector. The private sector seems less concerned about environmental and sustainable criteria than the public sector. If we look at the criteria that appear to not be used because of a lack of data, the majority of them are environmental and sustainability criteria. There also seemed to be a strong consensus that it would be useful to consider them, but to quote another participant "it is hard, almost impossible" to quantify them. The participants mentioned the use of these criteria described using standard benchmarks to evaluate them, but without giving them too much importance, as they would not be accurate/reliable data. At last, during the interview process, a few additional criteria were mentioned as being of value to be considered:

- The air quality in the surrounding environment, one interviewee mentioned it in relation to a school renovation;

- The lifecycle costing as opposed to the single event costing to have a more comprehensive costing evaluation;

- The visual or symbolic image of the building within its surroundings, it was mentioned a few times that year after year a building could become a symbol for the neighbourhood without having any inherent historical value;

- The overall reduction of the impact of the works, not limited to waste, this would include the noise, duration, soil occupation as well as the waste produced during the works.

\section{[Insert Fig. 5]}

The complete list of criteria is presented in the following Table 1, organised around six thematic categories. To analyse these criteria, the literature review suggested implementing an inclusive method, therefore executing a multicriteria analysis (MCA) instead of the more traditional CBA. The interviews' responses confirmed an interest in that direction: 11 positive to 2 negative. Several of the participants mentioned that some form of MCA is already being used, mostly to consider some environmental criteria that are harder to measure financially. However, this kind of MCA seems based on instinctive and subjective parameters that are not formalised or transparent, and therefore they cannot ensure consistency between decisions, nor support the dialogue with and between the stakeholders.

\section{[Insert Table 1]}

Another way in which the MCA seems to be used is to narrow down the first large-scale analysis to provide a top 3 or top 5 option that would then be further analysed only from a cost/benefit point of view, therefore providing a reinforcement to the CBA. The 2 negative responses came both from the private sector. Their reason was that a private owner would usually be more interested in getting a 
better return on investment than anything else, therefore only requiring a CBA, and they were confident that this is not likely to change in the future.

At this stage, the involvement of the stakeholders was investigated in relation to the attribution of weight/importance to each criterion. Similarly, to the previous stakeholders' involvement question, there was the most positive response: 8 against 5. Here too, there was a majority of participants from the public sector, leaning in favour of the stakeholders' involvement in this stage. Furthermore, it was mentioned a couple of times that the necessity of having stakeholders involved in this stage came from the fact that every stakeholder would have different needs. Therefore, to be able to satisfy as many stakeholders as possible, or at least to identify what option satisfies whom the consensus agreed on the importance of having the stakeholders' preferences included in the analysis stage.

\section{4 - PART 4: DIGITALISATION AND DATA ANALYTICS METHODS}

The last part of the interview process collected the opinions of the participants on the topic of the digitalisation of the construction industry, applied to the EOL decisions. Two main aspects were questioned: the digitalisation of the information flow, including data production and data analysis processes, and the digitalisation of the communication and sharing system. The consensus was very positive towards both aspects 10 and 12 positive responses, respectively. In both cases, there appeared to be a general understanding that we have already entered the digital era, and it is therefore "impossible if not stupid" trying to oppose it, as mentioned by one participant. The increased digitalisation was seen as positive for a number of reasons:

- Better visualisation of data during the DMP;

- Easier sharing of data through common data environment platforms;

- Resolve the long-distance collaboration between stakeholders;

- Enhance the collaboration between the stakeholders;

- Reduction of environmental impact by removing the paper throughout the process;

- Better conservation of the data over time.

However, some fears were expressed within both the positive and the negative responses. The major fear is about having the whole DMP replaced by machines. The importance of the human factor was frequently pointed out, the face-to-face interaction was still considered as fundamental. Other fears that were expressed concerning the doubts about the conservation of data (limited storage over time), the barriers to data sharing coming from coding compatibility issues, and the difficult management of data access parameters during the DMP. The last investigated element was the participants' identification of the fields where the future application of data analytics methods could be of major support in improving the measurement of criteria and the decision-making process. 
It was surprising and interesting to notice that the most recurring answer was that the future application of data analytics methods would bring the most benefit in measuring the environmental and energy criteria, which happen to be the same criteria that were mostly defined as being less used indeed because of a lack of data. , several participants mentioned that the interest in environmental issues has seen an increase in the last decade. This interest suggests that there is some hope that in the future, it will be possible to elaborate and give a more accurate measurement of the building's carbon footprint, both present and future; to quantify and better estimate the energy consumption of a building; and also, to quantify and define a value for recycling elements and materials during EOL interventions. The correspondence between the criteria not used because of the lack of data and the criteria that would benefit the most from the integration of data analytic methods was not a predictable result, although it was very much hoped for. The other two most recurring elements that were mentioned as benefiting from the future application of data analytics methods were the lifecycle costing and the early warning signals about the physical condition of the asset.

These results have overall validated the conceptual framework and allowed the design of the EOL DMP framework, presented in the next section.

\section{0 - EOL DMP FRAMEWORK}

The interview process served the purpose of validating the conceptual framework. The results of the interviews have validated:

- The process sequence and therefore the representation of the information flow with its main elements;

- The 18 evaluation criteria. It also provided more insight on the utilisation of each criterion in the current practice and the integration of some other criteria that had not been identified in the literature review;

- The use of MCA as the preferred analysis method, because the environmental concerns are currently shifting the focus of the stakeholders from purely financial criteria;

- The level of stakeholders' involvement within the DMP, as well as the stages when they can influence the process.

Following the validation of the conceptual framework, the EOL DMP framework was designed to better reflect the integration of the current practice of EOL decisions with the enhancements that BIM and advanced technologies could bring support to the DMP.

The EOL DMP framework has been organised to reflect the sequence of phases that compose the EOL DMP. Each phase identifies what digital processes would be involved, what data sources would 
be used, and what the actors involved actions would be. The sequence that defines the EOL DMP starts with the trigger event. The trigger event has been defined from the interviews. The events could come from either internal factors, stored in a digital model, or external factors, and have been identified in the interview results in Section 3.1. These factors would be identified as a trigger event by a machine learning system using big data analytics, and would notify the owner of the building through the asset manager. This is when the owner or their representatives would launch the EOL DMP.

The next step consists in defining the objectives the EOL intervention should have. The stakeholders involved would have, at this point, the possibility of expressing their needs concerning the fate of the building and any preferences on the route to take: renovation or demolition. A machine learning system could compute different reference parameters based on both the internal and external data of the building and the stakeholders' needs. This would be necessary to determine the feasible options that would then be analysed in more detail in the next step to identify the top 3 or top 5 options. The following step consists in the criteria analysis. This is where the most benefit could be drawn from the integration of big data analytics. The big data analytics would be able to identify and extract the relevant data from external and internal data sources, and combine them with the stakeholders' preferences, which would be reflected in the weight/importance given to each criterion.

Finally, an MCA would be run to provide a ranking of the options with trade-offs visualisation of what option fits best which stakeholder. This step is important because, since each stakeholder would have a different interest in the building's fate, the ranking of the options could present a different result based on which stakeholder's preferences are used as input. For example: the owner might be interested in only getting a good financial return, so the best option for them would be the one that would give them the highest financial return, but the trade-off might show that this option is the worst according to environmental criteria. Therefore, the owner could decide to choose a less financially advantageous option but having a better environmental score. Finally, the owner, or their representatives, are the ones taking the final decision. The best support the DMP can give them is to provide them with all the information needed to take an informed decision.

One of the interesting results from the interviews was that the internal and external data sources could serve 3 purposes depending on the phase of the DMP and depending on the digital process that is being used. The same data repository would be used to identify trigger events, would serve as the base to define the objectives of the feasible options, and would be used to estimate the measurement of the criteria during the MCA. The criteria needed to elaborate the MCA are presented in Table 1. They consist of the 18 criteria identified in the literature review, of which 2 have been rephrased, and 
3 criteria that were suggested during the interviews. The MCA would be the preferred analysis method used.

The purpose of the EOL DMP framework (see Fig. 6) is to identify, in the EOL DMP, where BIM and other advanced technologies would bring the most benefit and therefore be of support to the stakeholders involved in the DMP. The main advantage of BIM would be to provide an updated digital model of the building, containing the information from design through construction as well as O\&M. Furthermore, the main advantage of integrating advanced technologies would be to facilitate and increase the accuracy of the information and measurements, to allow stakeholders taking informed decisions. The framework is a model illustrating the interactions between actors, data, and analytical methods along the phases of the EOL DMP. As any model, it selects the most relevant aspects, leaving out a lot of details. In the next section, the findings around the framework, necessary to make a reasonable and smart usage of it are discussed.

[Insert Fig. 6]

\section{0 - DISCUSSION}

The EOL DMP framework proposes an answer to the research question about where the advanced digital and analytical technologies could be integrated into the EOL DMP to support the decision takers. The framework was designed based on the assumption that the advanced technologies described in the literature review will one day be implemented in buildings. However, this assumption rests on a few elements of discussion that only future times will be able to make light on.

\section{1 - PRACTICAL IMPLICATIONS}

Since this research was focused on tracking the information flow of the EOL DMP, it was not possible to investigate in depth the extent to which advanced technologies could bring benefit to each phase of the process. However, the biggest benefit of the introduction of advanced technologies in the DMP seems to be related to providing accurate measurements where accuracy is missing (Cahill et al., 2012, Palem, 2013, Bilal et al., 2016, Blanco et al., 2018, Haque et al., 2020). Based on the interview findings, the criteria that were most lacking accurate data were the environmental and energy criteria. Discussions arose about them and a majority of participants mentioned that unless calculation techniques, benchmarks, or standard criteria are better defined, it would be impossible to fully consider environmental aspects in the EOL DMP. Encouraging the implementation of the advanced digital technologies would probably benefit the whole lifecycle. Sensors could help tracking the structural stability of the building and the functionality of the services (Kim et al., 2010, Correa, 2015, Shalabi \& Turkan, 2017). If the sensors were then connected to an intelligent software with some 
notions of machine learning, it could be possible to identify issues and problems before they happen and therefore signal to the building operators the need of intervention (Correa, 2015, Ahmed et al., 2017, Whitlock-Glave et al., 2019). It was illustrated in the literature review that a building well maintained could have a longer life, therefore delaying EOL decisions and having a more positive impact on the environment (Fregonara et al., 2017). Furthermore, if the digital model of the building is regularly updated at every intervention, it would be possible to have an accurate data source of the internal data of the building. Another aspect to be mentioned is the fact that, if the EOL stage of a building's lifecycle was taken into account since the concept and design stage, there would be a benefit in applying more sustainable EOL options such as deconstruction and recycling (Lavy \& Jawadekar, 2014). Then, at the EOL stage, if the advanced technologies had previously been applied, it could be possible to have another intelligent software capable of identifying the relevant data from the digital model and elaborate an accurate measurement of the related criteria. If the intelligent software were to be further complemented with the machine learning algorithms, it could learn from previous experiences of other buildings and provide every time a better measurement (Blanco et al., 2018). The last element would be the integration of data analytics methods to run the appropriate calculations, and of determination algorithms to define the criteria measurement based on each stakeholders' preferences (Corry et al., 2011, Bilal et al., 2016, Shalabi \& Turkan, 2017).

If we look at the DMP as a whole, the criteria measurement was discussed as well. It appeared that a majority of the participants consider sufficient rough estimation of the criteria, claiming that the accuracy of the measurement does not need to go to the highest level of detail. Working with benchmarks was mentioned a few times as a must, especially concerning the external criteria as well as the environmental criteria. One could suggest that the integration of advanced technologies in every single EOL DMP would be an excessive and useless investment. To respond to such concerns, it should be considered that advanced technologies would be implemented first in some case studies. Their results could be used as benchmarks for common practice. The effect of increasing the accuracy of the benchmarks' calculation would already be an improvement and provide increased support to the EOL DMP. However, since every building is different, this situation would probably only be used as a transition between the old and the new way of assessing EOL situations.

\section{2 - THEORETICAL IMPLICATIONS}

The fundamental aspect to be retained in this whole hypothesis is that in order for it to be useful in the future, the interoperability of the different processes has to be guaranteed (Bilal et al., 2016). If the digital model cannot communicate with the maintenance tracking software or with the extracting and criteria analysis software, the whole process would become useless. Therefore, if these advanced technologies were to indeed be implemented, their interoperability will be the fundamental element 
to guarantee the success of the digitalisation of the EOL DMP. Another important element that came up during the interview process was that the external parameters were just as important as the internal parameters during the analysis stage. However, the issue here appeared to be related to the quantity of data. To develop a data source of the building's surroundings, the advanced technologies could be applied in a similar way but at a much larger scale. This is where the concept of smart cities would come to hand (Correa, 2015, Ahmed et al., 2017). Some of these technologies are now seeing the light and there are research going in that direction (Correa, 2015). It may not happen the way it is suggested in this research, but it seems likely enough that the construction industry will see the concept of smart cities happening.

\section{3 - POLICY IMPLICATIONS}

Policies could play a key role in order to smooth the process. On one side, new laws and regulations would be welcome to set standards and goals in the fields of digital technologies applications, energy consumption and sustainability in order to trigger the digital evolution in the EOL stage. On the other side, this research could be used to bring about the creation of a new $8^{\text {th }}$ stage to complete the RIBA Plan of Work. In fact, including an EOL stage in the theoretical model of a building's lifecycle is paramount to take it into account since the "Strategic Definition" Stage 0. EOL is, after all, an inescapable stage of the building's lifecycle (Lavy \& Jawadekar, 2014).

Finally, although it was not the focus of the research, the "fear of the new" appeared with great strength in the interviews. No matter how much technological improvements ease processes and support professionals, the fear of having people replaced by machines is tangible. It is the case in EOL situations, too. To overcome this fear, it would be important to demonstrate to professionals at all levels that the integration of advanced technologies should not imply the replacement of human workforce, but rather the evolution of the profession itself. Furthermore, if the advanced technologies were designed to work in conjunction with people and maybe even to learn to and from them, this may push back even more the fear that people have when technological implementations happen (Luna, 2020). Therefore, the suggestion would be not to overturn the EOL DMP, but to improve and/or replace the tools used throughout the process.

\section{0 - CONCLUSIONS}

In conclusion, the conceptual framework developed during this research provides an answer to the research question, by suggesting a paradigm to integrate BIM and digital analytical technologies into the current practice of EOL DMP. BIM technology would bring the benefit of providing the initial digital data source, from which machine learning and data analytics technologies would then extract the relevant data needed to measure accurately the criteria during the analysis of the EOL options. 
The originality of the framework lies in its capacity to connect the current practice with the technological advances that are happening in the construction industry.

\section{0 - FUTURE RESEARCH}

From a theoretic point of view, this research could help structure future research on EOL elements. It offers a bigger picture that could stimulate the collaboration of different research domains within the EOL stage. From a practical point of view, this framework could indicate the path to develop the software modules that are needed for the integration of digital technologies and existing tools. BIM and machine learning protocols already exist, as seen in the literature review; they only need the appropriate bridge to be able to work together.

Future research could explore the specificities of digital analytics to measure each key criterion. For example, how data from a network of sensors at each room temperature could be modelled and summarised to estimate recent energy consumption patterns and how they could change under a renovation option. Another research possibility would be to model the actual negotiation between stakeholders about the composition of a basket of key criteria: how to measure and how to weight them, in order to rank the relevant options on the table. Finally, there is the possibility to experiment the application of BIM and digital technologies to measure the criteria of Section 3.3, in order to set standards or benchmark values that would be reused parameters in the EOL options assessment of other buildings.

\section{REFERENCES}

Ahmed, V., Tezel, A., Aziz, Z., \& Sibley, M. (2017). The future of big data in facilities management: opportunities and challenges. Facilities, 35(13/14), 725-745.

Akinade, O., Oyedele, L., Oyedele, A., Davila Delgado, J. M., Bilal, M., Akanbi, L., Ajayi, A., \& Owolabi, H. (2020). Design for deconstruction using a circular economy approach: barriers and strategies for improvement. Production Planning and Control, 31(10), 829-840. https://doi.org/10.1080/09537287.2019.1695006

Asensio, A., Marco, Á., Blasco, R., \& Casas, R. (2014). Protocol and architecture to bring things into internet of things. International Journal of Distributed Sensor Networks, 10(4), 158252.

Baker, H., Moncaster, A., \& Al-Tabbaa, A. (2017). Decision-making for the demolition or adaptation of buildings. Proceedings of the Institution of Civil Engineers - Forensic Engineering, 170(3), 144-156. https://doi.org/10.1680/jfoen.16.00026

Bell, J. (2014). Doing Your Research Project: A guide for first-time researchers. McGraw-Hill 
Education (UK).

Bender, B. (2019). The Determinants of Housing Demolition and Abandonment The Determinants of Housing Demolition and Abandonment *. Southern Economic Journal, 46(1), 131-144.

Beria, P., Maltese, I., \& Mariotti, I. (2012). Multicriteria versus Cost Benefit Analysis: A comparative perspective in the assessment of sustainable mobility. European Transport Research Review, 4(3), 137-152. https://doi.org/10.1007/s12544-012-0074-9

Bilal, M., Oyedele, L. O., Qadir, J., Munir, K., Ajayi, S. O., Akinade, O. O., Owolabi, H. A., Alaka, H. A., \& Pasha, M. (2016). Big Data in the construction industry: A review of present status, opportunities, and future trends. Advanced Engineering Informatics, 30(3), 500-521.

Blanco, J. L., Fuchs, S., Parsons, M., \& Ribeirinho, M. J. (2018). ARTIFICIAL INTELLIGENCE: CONSTRUCTION TECHNOLOGY'S NEXT FRONTIER. Building Economist, 7-13. http://search.ebscohost.com/login.aspx?direct=true\&db=bth\&AN=133469865\&site=ehost-live

Braun, V., \& Clarke, V. (2006). Using thematic analysis in psychology. Qualitative research in psychology, 3(2), 77-101.

Bullen, P., \& Love, P. (2011). A new future for the past: a model for adaptive reuse decision-making. Built Environment Project and Asset Management, 1(1), 32-44. https://doi.org/10.1108/20441241111143768

Buyle, M., Braet, J., \& Audenaert, A. (2013). Life cycle assessment in the construction sector: A review. In Renewable and Sustainable Energy Reviews (Vol. 26, pp. 379-388). Pergamon. https://doi.org/10.1016/j.rser.2013.05.001

Cahill, B., Menzel, K., \& Flynn, D. (2012). BIM as a centre piece for optimised building operation. EWork and EBusiness in Architecture, Engineering and Construction - Proceedings of the European Conference on Product and Process Modelling 2012, ECPPM 2012, 549-555. https://doi.org/10.1201/b12516-88

Callow, D., Lee, J., Blumenstein, M., Guan, H., \& Loo, Y. C. (2013). Development of hybrid optimisation method for Artificial Intelligence based bridge deterioration model - Feasibility study. Automation in Construction, 31, 83-91. https://doi.org/10.1016/j.autcon.2012.11.016

Chantrelle, F. P., Lahmidi, H., Keilholz, W., Mankibi, M. El, \& Michel, P. (2011). Development of a multicriteria tool for optimizing the renovation of buildings. Applied Energy, 88(4), 13861394. https://doi.org/10.1016/j.apenergy.2010.10.002

Chau, C. K., Xu, J. M., Leung, T. M., \& Ng, W. Y. (2017). Evaluation of the impacts of end-of-life management strategies for deconstruction of a high-rise concrete framed office building. Applied 
Energy, 185, 1595-1603.

CORDIS. (2018a, October 1). Building Information Modelling based tools \& technologies for fast and efficient RENovation of residential buildings | BIM4REN Project. https://cordis.europa.eu/project/id/820773

CORDIS. (2018b, November 1). Harmonised Building Information Speedway for Energy-Efficient Renovation | BIM-SPEED Project. https://cordis.europa.eu/project/id/820553

CORDIS. (2019a, January 1). BIM-based holistic tools for Energy-driven Renovation of existing Residences | BIMERR Project. https://cordis.europa.eu/project/id/820621

CORDIS. (2019b, January 1). BIM based fast toolkit for Efficient rEnovation in Buildings $\mid$ BIM4EEB Project. https://cordis.europa.eu/project/id/820660

CORDIS. (2019c, January 1). ENergy aware BIM Cloud Platform in a COst-effective Building REnovation Context | ENCORE Project. https://cordis.europa.eu/project/id/820434

Correa, F. R. (2015). Is BIM big enough to take advantage of big data analytics? ISARC. Proceedings of the International Symposium on Automation and Robotics in Construction, 32, 1.

Corry, E., Keane, M., O’Donnell, J., \& Costa, A. (2011). Systematic development of an operational BIM utilising simulation and performance data in building operation. Proceedings of Building Simulation 2011: 12th Conference of International Building Performance Simulation Association, 1422-1429.

Djamba, Y. K., \& Neuman, W. L. (2002). Social Research Methods: Qualitative and Quantitative Approaches. Teaching Sociology, 30(3), 380. https://doi.org/10.2307/3211488

European Commission. (2018, October 31). Building information modelling adapted to efficient renovation (RIA). https://cordis.europa.eu/programme/id/H2020_LC-EEB-02-2018

Fregonara, E., Giordano, R., Ferrando, D. G., \& Pattono, S. (2017). Economic-environmental indicators to support investment decisions: A focus on the buildings' end-of-life stage. Buildings, 7(3), 65.

Gao, X., \& Pishdad-Bozorgi, P. (2019, January 1). BIM-enabled facilities operation and maintenance: A review. Advanced Engineering Informatics, 39, 227-247. https://doi.org/10.1016/j.aei.2019.01.005

Han, K. K., \& Golparvar-Fard, M. (2015). Appearance-based material classification for monitoring of operation-level construction progress using 4D BIM and site photologs. Automation in Construction, 53, 44-57. https://doi.org/10.1016/j.autcon.2015.02.007 
Haque, M. E., Asikuzzaman, M., Khan, I. U., Ra, I.-H., Hossain, M. S., \& Shah, S. B. H. (2020). Comparative Study of IoT-Based Topology Maintenance Protocol in a Wireless Sensor Network for Structural Health Monitoring. Remote Sensing, 12(15), 2358. https://doi.org/10.3390/rs12152358

Holzwarth, V., Schneider, J., Kunz, A., \& vom Brocke, J. (2019). Data driven value creation in AEC along the building lifecycle. Journal of Physics: Conference Series, 1343(1), 12046.

Hübner, F., Volk, R., Kühlen, A. and Schultmann, F. (2017). Review of project planning methods for deconstruction projects of buildings. Built Environment Project and Asset Management (Vol. 7 No. 2, pp. 212-226). https://doi.org/10.1108/BEPAM-11-2016-0075

Ilter, D., \& Ergen, E. (2015). BIM for building refurbishment and maintenance: current status and research directions. In Structural Survey (Vol. 33, Issue 3, pp. 228-256). Emerald Group Publishing Ltd. https://doi.org/10.1108/SS-02-2015-0008

Kim, J. H., Sharma, G., Boudriga, N., \& Iyengar, S. S. (2010). SPAMMS: A sensor-based pipeline autonomous monitoring and maintenance system. 2010 2nd International Conference on COMmunication Systems and NETworks, COMSNETS 2010. https://doi.org/10.1109/COMSNETS.2010.5432015

Lavy, S., \& Jawadekar, S. (2014). A Case Study of Using BIM and COBie for Facility Management. International Journal of Facility Management, 5(2).

Luna, R. (2020). Audrey (Hepburn), l'antenata di Alexa e Siri. E non è finita qui - la Repubblica. La Repubblica. $\quad$ https://www.repubblica.it/dossier/stazione-futuro-riccardoluna/2020/08/03/news/audrey_hepburn_1_antenata_di_alexa_e_siri_e_non_e_finita_qui$263561800 /$

Marleau Donais, F., Abi-Zeid, I., Waygood, E. O. D., \& Lavoie, R. (2019). A review of cost-benefit analysis and multicriteria decision analysis from the perspective of sustainable transport in project evaluation. EURO Journal on Decision Processes, 7(3-4), 327-358. https://doi.org/10.1007/s40070-019-00098-1

Martín-Martín, A., Orduna-Malea, E., Thelwall, M., \& López-Cózar, E. D. (2018, August 15). Google Scholar, Web of Science, and Scopus: a systematic comparison of citations in 252 subject categories. https://doi.org/10.31235/osf.io/42nkm

Medineckiene, M., \& Björk, F. (2011). Owner preferences regarding renovation measures - The demonstration of using multi-criteria decision making. Journal of Civil Engineering and Management, 17(2), 284-295. https://doi.org/10.3846/13923730.2011.582380 
Motawa, I., \& Almarshad, A. (2013). A knowledge-based BIM system for building maintenance. Automation in Construction, 29, 173-182. https://doi.org/10.1016/j.autcon.2012.09.008

Naderifar, Mahin \& Goli, Hamideh \& Ghaljaei, Fereshteh. (2017). Snowball Sampling: A Purposeful Method of Sampling in Qualitative Research. Strides in Development of Medical Education. In Press. 10.5812/sdme.67670

Nakama, Y., Onishi, Y., \& Iki, K. (2015). Development of building information management system using BIM toward strategic building operation and maintenance. In Y. Ikeda, C. M. Herr, D. Holzer, S. Kaijima, M. J. Kim, \& M. A. Schnabel (Eds.), Emerging Experience in Past, Present and Future of Digital Architecture.

Palem, G. (2013). CONDITION-BASED MAINTENANCE USING SENSOR ARRAYS AND TELEMATICS. International Journal of Mobile Network Communications \& Telematics, 3(3), 19-28. https://doi.org/10.5121/ijmnct.2013.3303

Rabatel, J., Bringay, S., \& Poncelet, P. (2011). Anomaly detection in monitoring sensor data for preventive maintenance. Expert Systems with Applications, 38(6), 7003-7015. https://doi.org/10.1016/j.eswa.2010.12.014

RIBA. (2020). RIBA Plan of Work 2020 Overview. www.ribaplanofwork.com

Robinson, O. C. (2014). Sampling in Interview-Based Qualitative Research: A Theoretical and Practical Guide. Qualitative Research in Psychology, 11(1), 25-41. https://doi.org/10.1080/14780887.2013.801543

Rosenfeld, Y., \& Shohet, I. M. (1999). Decision support model for semi-automated selection of renovation alternatives. Automation in Construction, 8(4), 503-510.

Roy, B. (1985). Méthodologie multicritère d'aide à la décision (Economica (ed.)).

Saarikoski, H., Mustajoki, J., Barton, D. N., Geneletti, D., Langemeyer, J., Gomez-Baggethun, E., Marttunen, M., Antunes, P., Keune, H., \& Santos, R. (2016). Multi-Criteria Decision Analysis and Cost-Benefit Analysis: Comparing alternative frameworks for integrated valuation of $\begin{array}{lllll}\text { ecosystem } & \text { services. } & \text { Ecosystem } & \text { 238-249. }\end{array}$ https://doi.org/10.1016/j.ecoser.2016.10.014

Shalabi, F., \& Turkan, Y. (2017). IFC BIM-Based Facility Management Approach to Optimize Data Collection for Corrective Maintenance. Journal of Performance of Constructed Facilities, 31(1). https://doi.org/10.1061/(ASCE)CF.1943-5509.0000941

Stage, E., Fregonara, E., \& Giordano, R. (2017). Economic-Environmental Indicators to Support Investment Decisions : A Focus on the Buildings '. https://doi.org/10.3390/buildings7030065 
Thomsen, A., \& Flier, K. Van Der. (2008). Replacement or reuse? The choice between demolition and life cycle extension from a sustainable viewpoint. ENHR International Research Conference Shrinking Cities, Sprawling Suburbs, Changing Country Sides, July. http://repository.tudelft.nl/assets/uuid:a670a506-74e6-4c4e-b7b6-71107fb9778d/219624.pdf

Tupenaite, L., Zavadskas, E. K., Kaklauskas, A., Turskis, Z., \& Seniut, M. (2010). Multiple criteria assessment of alternatives for built and human environment renovation. Journal of Civil Engineering and Management, 16(2), 257-266. https://doi.org/10.3846/jcem.2010.30

Van Nederveen, G. A., \& Tolman, F. P. (1992). Modelling multiple views on buildings. Automation in Construction, 1(3), 215-224. https://doi.org/10.1016/0926-5805(92)90014-B

Velasquez, M., \& Hester, P. (2013). An analysis of multi-criteria decision making methods. International Journal of Operations Research, 10(2), 56-66.

Vieira, P. S., \& Horvath, A. (2008). Assessing the end-of-life impacts of buildings. ACS Publications.

Vincke, P. (1989). L'aide multicritère de la décision (Université de Bruxelles (ed.)).

Volk, R., Stengel, J., \& Schultmann, F. (2014). Building Information Modeling (BIM) for existing buildings-Literature review and future needs. Automation in Construction, 38, 109-127. https://doi.org/10.1016/j.autcon.2013.10.023

Whitlock-Glave, H. C., Jansen, S. B., Weigle, H. L., Brown, L. D., \& Capp, M. A. (2019). The Technology Revolution in the Construction Industry: The Rise of Artificial Intelligence. Illinois Association Defense Trial Counsel Quarterly, 29(4), 1-34. www.iadtc.org

Yin, H., Stack, P., \& Menzel, K. (2011). Decision support for building renovation strategies. In Computing in Civil Engineering (2011) (pp. 834-841).

Zhengwei, L., \& Gongsheng, H. (2013). Preventive approach to determine sensor importance and maintenance requirements. Automation in Construction, 31, 307-312. https://doi.org/10.1016/j.autcon.2012.12.008 


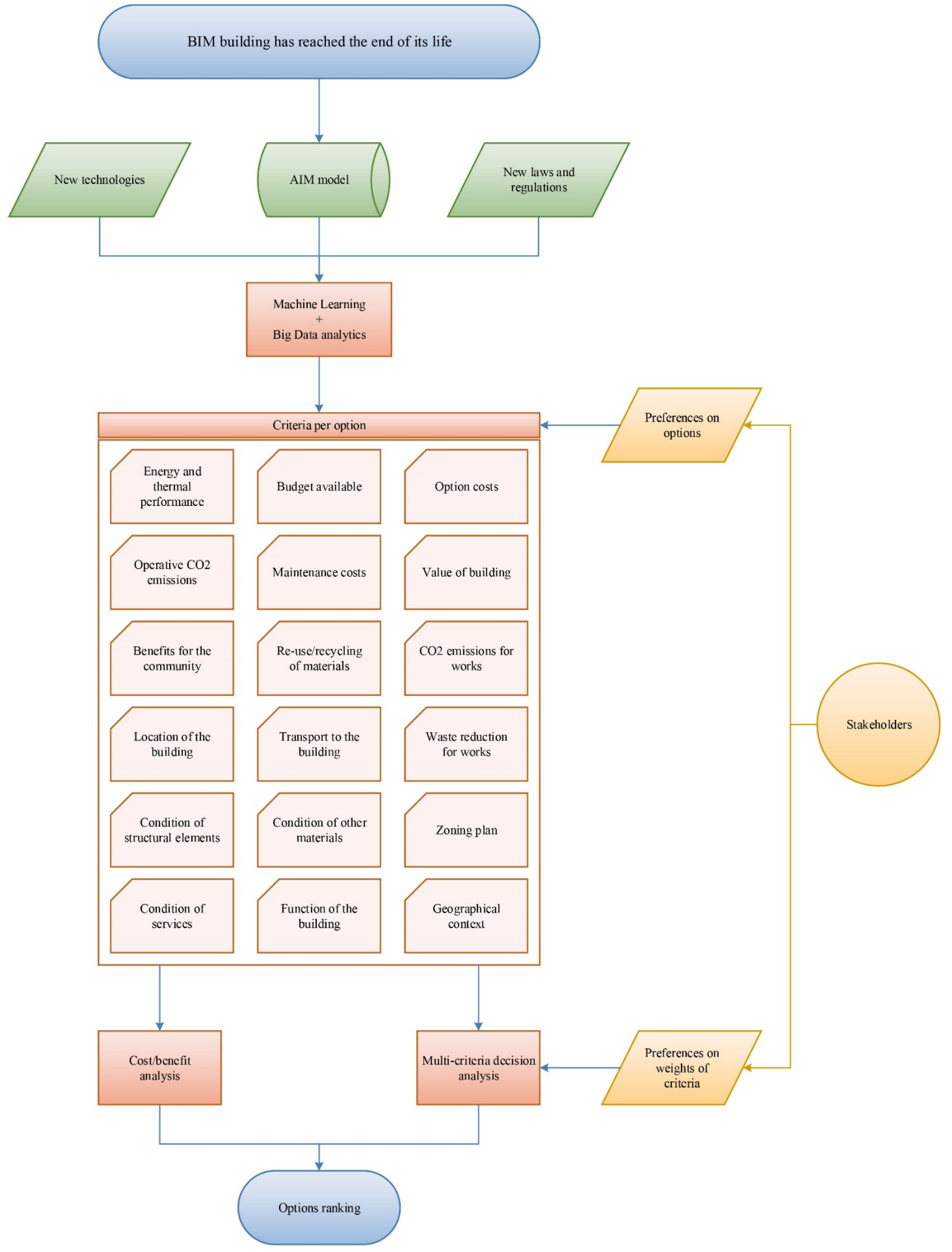

Figure 1. Conceptual framework 


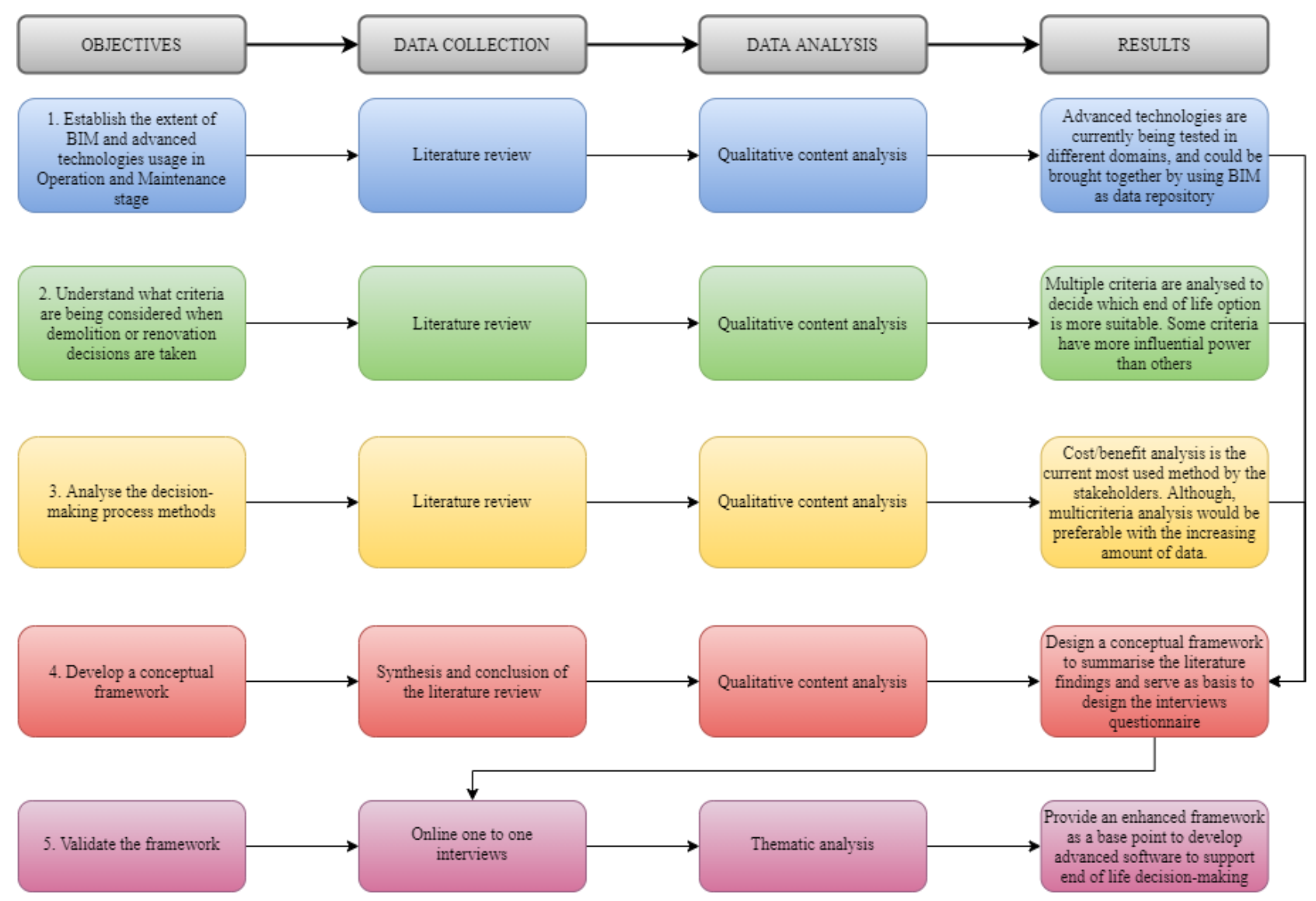

Figure 2. Methodology flowchart

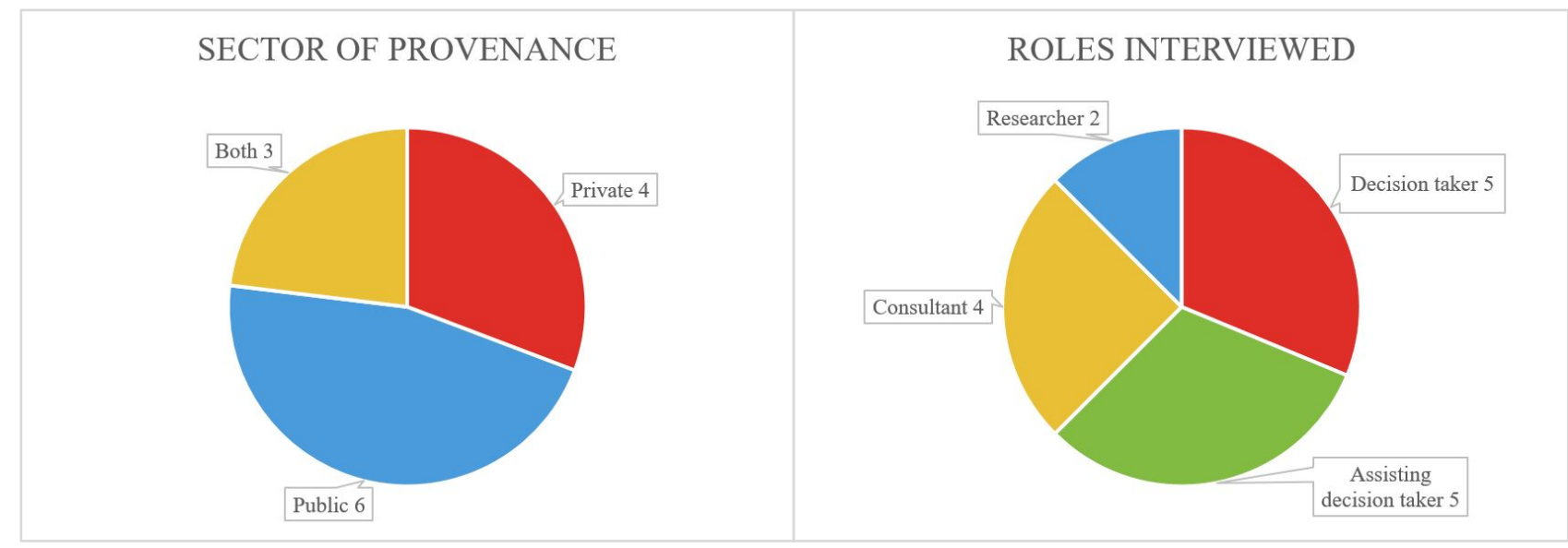

Figure 3. Participants' background by sector and by roles 


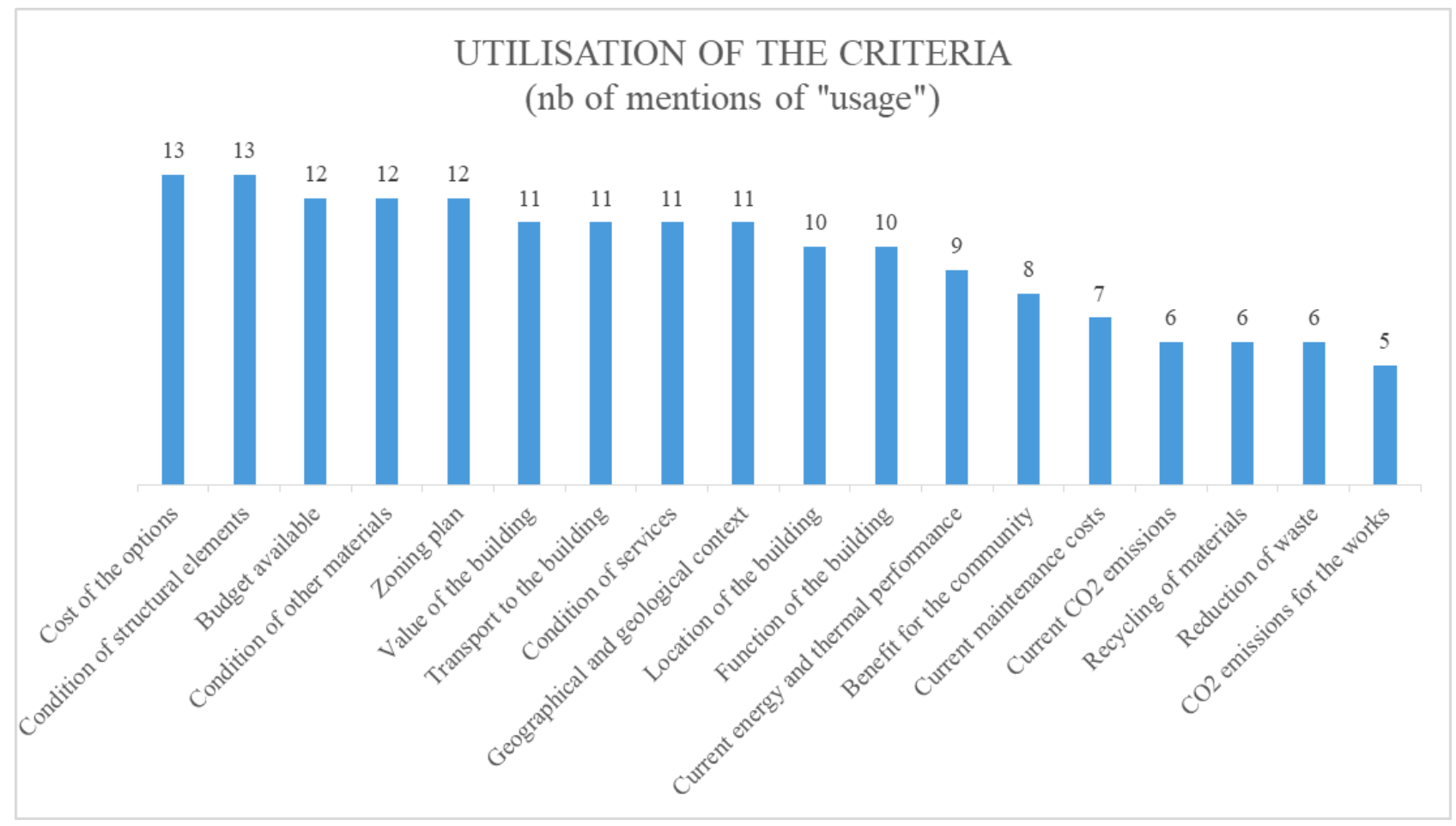

Figure 4. Ranking of used criteria by mentions of "usage"

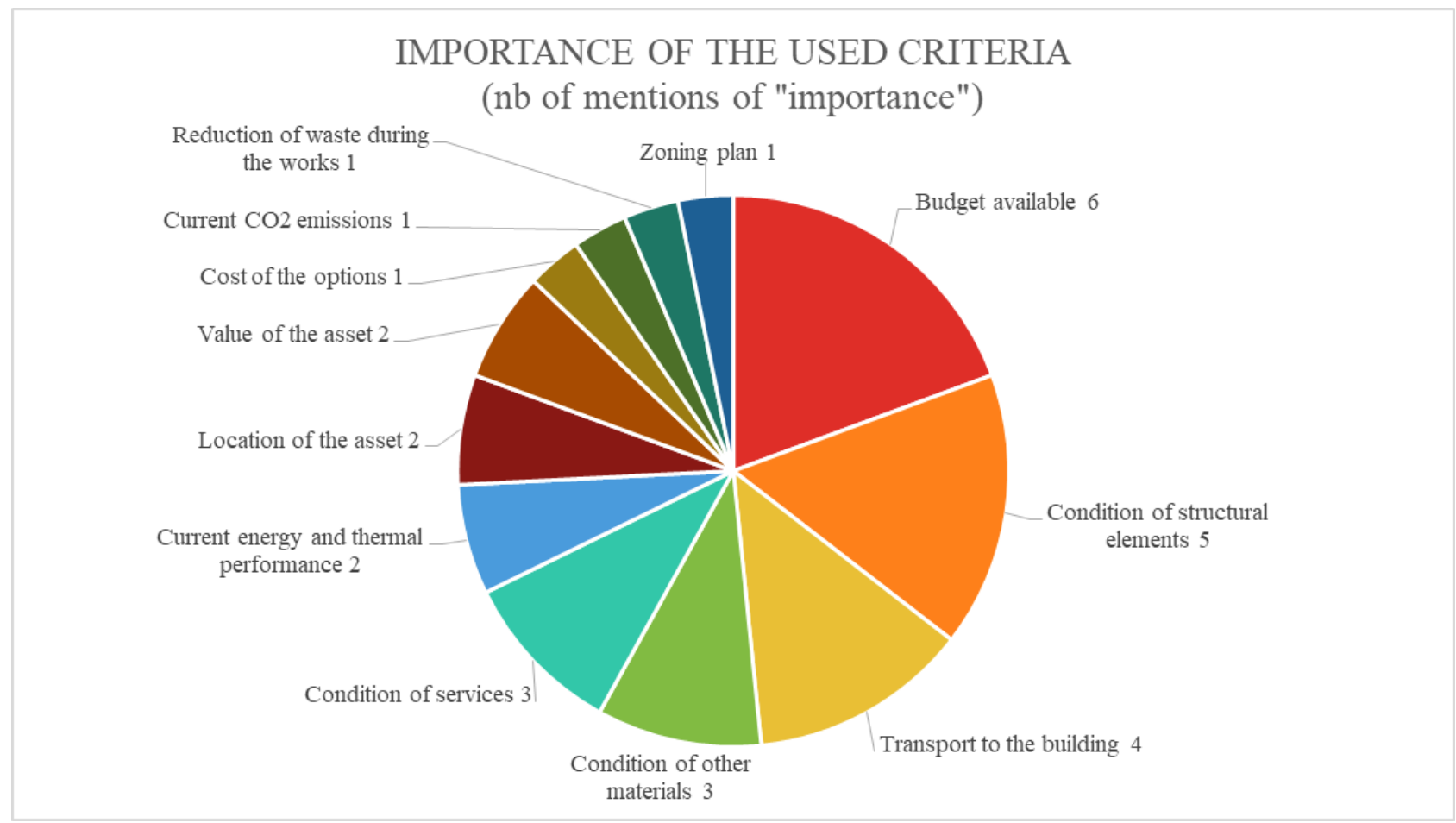

Figure 5. Ranking of used criteria by mentions of "importance" 

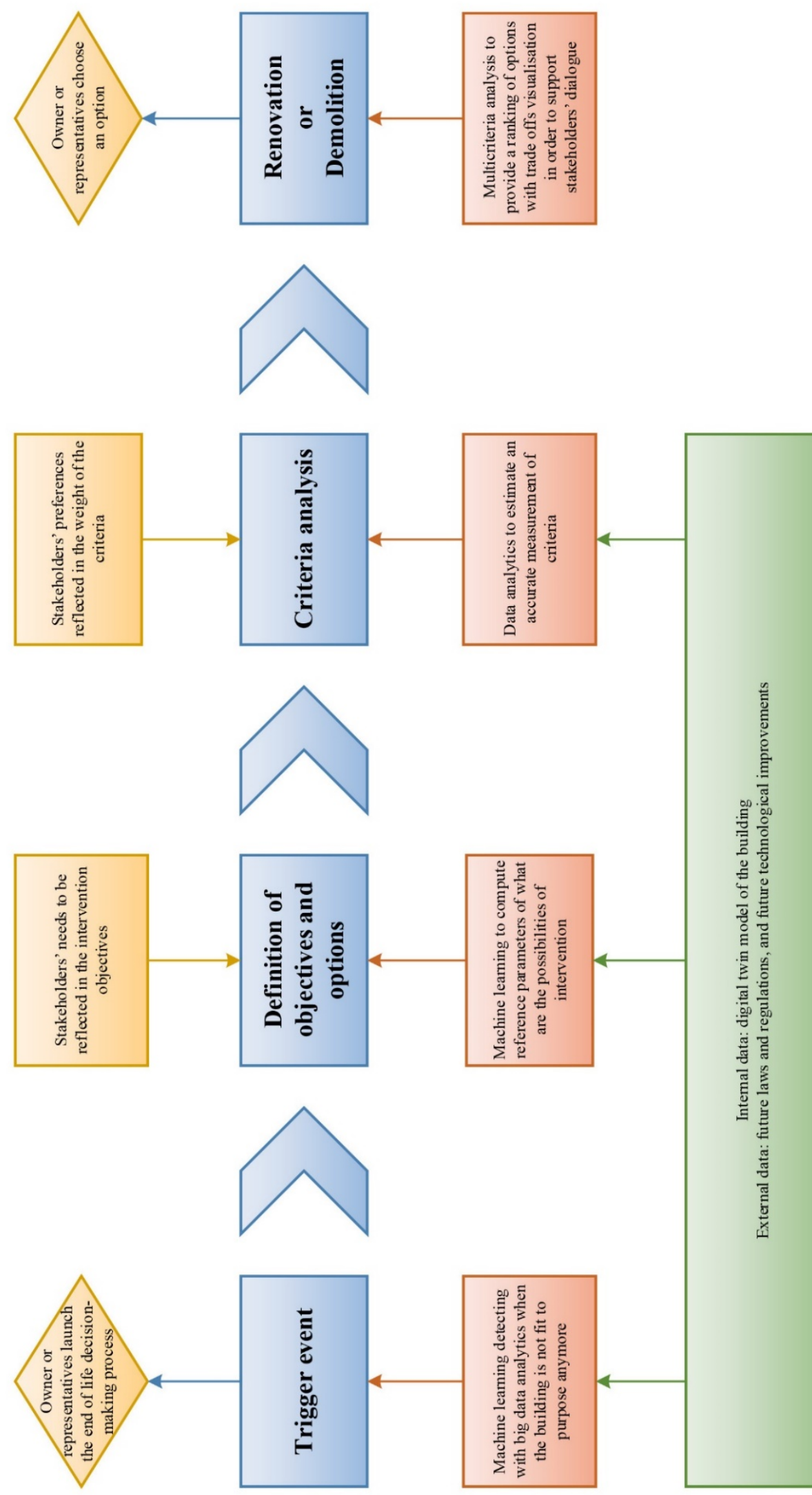
Table 1. Final set of decision criteria

\begin{tabular}{|c|c|c|}
\hline PHYSICAL CONDITION & ENVIRONMENTAL & URBAN REALM \\
\hline $\begin{array}{l}\text { Condition of structure } \\
\text { Condition of other materials } \\
\text { Condition of services } \\
\text {. Function of building }\end{array}$ & $\begin{array}{l}\cdot \text { Recycling of materials } \\
\cdot \text { Carbon footprint of works } \\
\cdot \text { Reduction of impact of works } \\
\text { (time, waste, noise, ecc...) }\end{array}$ & $\begin{array}{l}\cdot \text { Urban planning } \\
\cdot \text { Visual/symbolic identity } \\
\cdot \text { Geographical/geological context } \\
\cdot \text { Air quality }\end{array}$ \\
\hline FINANCIAL & ENERGY & SOCIAL \\
\hline $\begin{array}{l}\text { Budget available } \\
\text { - Cost of options } \\
\text { Cost of current maintenance } \\
\text { - Residual value of building/land } \\
\text { Lifecycle costing }\end{array}$ & $\begin{array}{l}\cdot \text { Current energy and thermal } \\
\text { performance } \\
\cdot \text { Current carbon footprint }(\mathrm{CO} 2 \\
\text { emissions) }\end{array}$ & $\begin{array}{l}\text { Benefit for the community } \\
\text { Location of the building } \\
\text { Transport to access the building }\end{array}$ \\
\hline
\end{tabular}

